\title{
Aspectos contratuais no âmbito das startups
}

\section{Contractual aspects in the scope of startups}

Aspectos contractuales en el ámbito de las startups

\section{Resumo}

A contratação das startups segue um rito básico, mas com nuances peculiares, sendo assinatura de uma carta de intenções, seguido pela assinatura de um acordo de confidencialidade, posteriormente o processo de auditoria e, por fim, a assinatura do termo de investimento. Nessa perspectiva, este artigo, através da pesquisa exploratória, de natureza qualitativa, método dedutivo, coleta de dados bibliográfico-documental, procedeu-se de modo a realizar uma análise acerca dos contratos no âmbito das startups como forma de dar alicerce e incentivar as atividades desempenhadas na esfera das startups, sobretudo no que tange a segurança jurídica e crescimento econômico. Ademais, cabe pontuar a horizontalidade das normas fundamentais do ordenamento jurídico brasileiro, assim, o relacionamento entre investidor e startup-investida também deve respeito a carga axiológica. Por fim, diante da problemática exposta, buscou-se, embasado nos instrumentos jurídicos empresarias, elucidar a necessidade dos empresários, pautado na segurança jurídica e no respeito crescimento econômico, buscar a utilizar os instrumentos jurídicos como forma de promoção econômica.

Palavras-chave: Contrato; Startups; Crescimento econômico.

\begin{abstract}
The hiring of startups follows a basic rite, but with peculiar nuances, being the signing of a letter of intent, followed by the signing of a confidentiality agreement, later the audit process and, finally, the signing of the investment term. In this perspective, this article, through exploratory research, of a qualitative nature, deductive method, collection of bibliographic-documental data, proceeded in order to carry out an analysis on contracts within the scope of startups as a way of providing a foundation and encouraging activities performed in the sphere of startups, especially with regard to legal security and economic growth. In addition, it is worth pointing out the horizontality of the fundamental norms of the Brazilian legal system, thus, the relationship between investor and startup-investee must also respect the axiological load. Finally, in view of the exposed problem, it was sought, based on corporate legal instruments, to elucidate the need for businessmen, based on legal security and respect for economic growth, to seek to use legal instruments as a form of economic promotion.
\end{abstract}

Keywords: Contract; Startups; Economic growth.

\section{Resumen}

La contratación de startups sigue un rito básico, pero con matices peculiares, siendo la firma de una carta de intenciones, seguida de la firma de un acuerdo de confidencialidad, posteriormente el proceso de auditoría y, finalmente, la firma del plazo de inversión. En esta perspectiva, se procedió a este artículo, a través de una investigación exploratoria, de carácter cualitativo, método deductivo, recolección de datos bibliográfico-documental, con el fin de realizar un análisis de los contratos en el ámbito de las startups como forma de fundamentar y alentar actividades realizadas en el ámbito de las startups, especialmente en materia de seguridad jurídica y crecimiento económico. Además, cabe señalar la horizontalidad de las normas fundamentales del ordenamiento jurídico brasileño, por lo que la relación entre inversor y startup-participada también debe respetar la carga axiológica. Finalmente, ante el problema expuesto, se buscó, con base 
en instrumentos jurídicos corporativos, dilucidar la necesidad de que los empresarios, basados en la seguridad jurídica y el respeto al crecimiento económico, busquen utilizar los instrumentos legales como forma de promoción económica.

Palabras clave: Contrato; Inauguración; Crecimiento economico.

\section{Introdução}

O processo perseguido para realizar o aporte e as nuances jurídicas enfrentadas pelas startups é um rito básico, mas com questões peculiares, que quando da contratação, realizam-se os seguintes passos: i) assinatura de uma carta de intenções (term sheet); ii) assinatura de um acordo de confidencialidade (Non-Disclousure Agreement - NDA); iii) processo de auditoria (due diligence); iv) assinatura do termo de investimento (Feigelson, Fontenele \& Fonseca, 2018, p. 118).

Nessa esteira, é extremamente necessário destacar a horizontalidade das normas fundamentais do ordenamento jurídico brasileiro. Haja vista esses serem dispositivos previstos na Constituição Federal, texto de natureza preponderantemente pública, há sobre essa carga axiológica constitucional uma incidência que extrapola as relações de direito público, para produzir uma eficácia também sobre as relações privadas.

Os direitos fundamentais, de previsão constitucional, portanto, positivados em norma de natureza essencialmente pública, deverão ter eficácia também sobre as reações privadas, passando a ser de observância obrigatória também pelos particulares quando se relacionarem entre si.

É decorrência, portanto, deste raciocínio, que se fala em valorização da dignidade da pessoa humana como mantra superior, do qual decorre uma série de outros princípios de aplicabilidade imediata sobre as relações negociais. Dessa forma, o relacionamento entre investidor e startup-investida também deve respeito a carga axiológica.

Tendo em vista a relevância do tema proposto, será realizada uma pesquisa exploratória, que tem por objetivo proporcionar uma maior familiaridade com o problema. Sem a perspectiva de esgotamento do tema, tratar-se-á, sobretudo, acerca dos aspectos contratuais no âmbito das startups. Ademais, se utilizará do método de abordagem dedutivo, uma vez que se buscará os resultados a partir da análise geral até concluir de maneira particular a hipótese. Quanto à natureza da pesquisa, esta será qualitativa, buscar-se-á analisar e interpretar os institutos do Direito Empresarial, como forma de chegar à conclusão de que é possível adotar um mecanismo capaz de impulsionar a atividade empresarial, pautado na livre concorrência e no desenvolvimento econômico.

Quanto ao método de procedimento, atribuir-se-á o método monográfico, partindo de um estudo profundo sobre as startups, que podendo esta pesquisa ser considerada representativa de muitos outros ou mesmo de todos os casos semelhantes. Além do mais, quanto aos procedimentos técnicos, se delineará o presente estudo por meio de pesquisa bibliográfica e documental, tendo em vista que se buscará, através da renomada doutrina do direito e periódicos especializados, bem como através da interpretação das leis, a solução para impulsionar o desenvolvimento econômico.

No presente trabalho, portanto, serão apresentados alguns apontamentos acerca dos aspectos contratuais no âmbito das startups, sobretudo no que tange as questões peculiares de contratação.

\section{Desenvolvimento}

O term sheet é um ato pré-contratual, em que as partes elaboram uma carta que possui as intenções e premissas que irão conduzir o futuro contrato de financiamento a ser celebrado. É um acordo preliminar, em que reúne os princípios e cláusulas principais que estarão presentes no instrumento de investimento que pode ser realizado ao final desse procedimento (Rebelo, 2013).

Nesse diapasão, é salutar pontuar que a Constituição de 1988 foi recheada por princípios e normas que valorizam a solidariedade, justiça e dignidade da pessoa humana, diretrizes que foram refletidas no Código Civil brasileiro de 2002. Não há 
divergência cabível sobre essa afirmação, pois a operabilidade, socialidade e eticidade (Tepedino, 2002, p. 357) foram positivadas como princípios norteadores da legislação civil, o que reforça essa inteligência.

Assim, a boa-fé objetiva foi o instrumento escolhido pelo legislador para desempenhar uma função de equidade e humanização nas relações sociais. É nesse sentido que se exige a estrita observação de: a) dever de proteção; b) dever de informação, advertir, explicar, esclarecer, avisar, prestar contas; c) dever de cooperação: visando ensejar confiança nessa relação, a reunião de condições para tal realização (Ehrhardt, 2014, p. 97).

A decorrência lógica dessa afirmação transcorre do artigo 113 do Código Civil, quando este afirma que "os negócios jurídicos devem ser interpretados conforme a boa-fé e os usos do lugar de sua celebração" (Brasil, 2002). Isso porque o artigo 187, da mesma legislação, estipula ilicitude civil para a prática irregular do exercício de um direito, quando o seu titular extrapola os limites econômicos, sociais delineados pela boa-fé e bons costumes ${ }^{1}$.

O princípio da boa-fé objetiva possui peso normativo que invoca um dever, uma exigência que é socialmente recomendada e exigida. Um compromisso de conduta de não frustrar a confiança alheia, muitas vezes se confundindo com a equidade das relações negociais

A complexidade das obrigações, que tem anexado aos deveres principais obrigações secundárias e laterais, que impõe aos contratantes padrões de conduta no relacionamento, a exemplo de deveres de cooperação, lealdade, informação, dentre outros, trouxe a figura da violação positiva dos contratos, capaz de gerar responsabilidade civil para eventuais violadores.

Só há adimplemento pleno quando houver cumulativamente o cumprimento da obrigação principal e dos deveres anexos aos negócios jurídicos. Foi na tentativa de evitar o adimplemento ruim das obrigações que o legislador estipulou essas regras. Logo, ao celebrar um contrato, os participantes deverão cumprir não apenas com a obrigação imediata, principal, mas também com os deveres conexos e secundários que passam a integralizar o sistema obrigacional.

Isso faz com que a violação positiva do contrato se torne uma modalidade de inadimplemento obrigacional, cuja obrigação principal carrega deveres extras que devem ser igualmente executados, posto que são eles os definidores objetivos da conduta de boa-fé de um agente.

(...) a violação positiva do contrato, no direito brasileiro, corresponde ao inadimplemento decorrente do descumprimento de dever lateral, quando este dever não tenha uma vinculação direta com os interesses do credor na prestação. (Pereira, 2001, p. 266).

Nessa seara, embora o term sheet não seja um instrumento contratual principal, deve ser considerado negócio jurídico latu sensu para o ordenamento civil, de modo que impera sobre ele o princípio da boa-fé objetiva, que conforme artigo 422 do Código Civil, a sua não observância pode levar a sanções civis: "Art. 422. Os contratantes são obrigados a guardar, assim na conclusão do contrato, como em sua execução, os princípios de probidade e boa-fé" (Brasil, 2002).

Assim, potenciais investidores e investidos, quando sentarem para realizar as discussões preliminares de eventual contratação de investimento, deve haver para ambas as partes a observância da boa-fé objetiva, que seriam deveres de lealdade, confiança, retidão, probidade, sob pena de responder civilmente pela violação positiva do contrato.

Já há inclusive posicionamento recente do Superior Tribunal de Justiça, que no julgamento do Recurso Especial no

1 Art. 187. Também comete ato ilícito o titular de um direito que, ao exercê-lo, excede manifestamente os limites impostos pelo seu fim econômico ou social, pela boa-fé ou pelos bons costumes. 
$1309972^{2}$, de origem do estado de São Paulo, reconheceu o dever de responsabilizar em função da quebra de confiança, originada pela expectativa legítima em determinado comportamento, ainda em fase pré-contratual.

O caso ora comentado foi um litígio que chegou àquela corte através da interpelação de um recurso apresentado pela Radiall do Brasil e teve como recorridos a IBM-Brasil e PCI Componente. Segundo os autos, embora eventual contrato formal não tenha sequer se concretizado e existido para o mundo jurídico, ambas as partes estabeleceram relações preliminares aprofundadas, onde a IBM se comportou nessas tratativas como negociante, chegando a apresentar projetos e enviando para a autora recursal especificações técnicas de produto que deveria vir a ser fabricado, dentro das condições do negócio, gerando uma expectativa legítima de contratação, o que não veio a se concretizar.

Essa confiança depositada fez com que a Radiall chegasse a realizar investimentos em sua estrutura na esperança de que tais fatos projetados nas tratativas viriam se concretizar, o que não ocorreu, de forma repentina e surpreendente.

Assim, diante da frustração contratual que não foi levada adiante, a companhia prejudicada ingressou com ação judicial cobrando o ressarcimento dos danos materiais suportados em virtude da quebra de confiança. O pedido foi julgado procedente em primeiro e segundo grau, e em sede recursal, o Superior Tribunal de Justiça manteve a condenação do tribunal inferior.

Sob a fundamentação de homenagear a Teoria da Confiança, a corte superior reconheceu a responsabilidade civil em função da quebra de confiança entre as partes do contrato, que se distingue como uma modalidade autônoma, em relação às responsabilidades contratual e extracontratual, conforme posicionamento pacífico da doutrina e também da jurisprudência.

Ficou reconhecido o respectivo dever de indenizar, porque há sobre o dever decorrente da boa-fé um interesse público e coletivo de que as partes se comportem a não lesar o interesse do outro e os bons costumes nas relações sociais, a exemplo do comportamento de probidade, que transcende a esfera dos interesses privados.

Assim, "uma vez identificada a violação aos deveres conexos do negócio jurídico, o devedor se constitui em mora, em virtude do adimplemento ruim, ou não-satisfativo, ainda que venha a adimplir a obrigação principal" (Azevedo \& Maia, 2015, p. 124). Dessa forma, gera para o lesado a opção de buscar a respectiva recompensa por eventuais perdas e danos que venha a sofrer.

Em homenagem ao princípio pacta sunt servanda, deve-se procurar sempre a manutenção do contrato e das obrigações principais, em função da relevância que desempenha para a sociedade, fazendo com que este seja preservado, mas diante de eventuais violações de deveres anexos, estes devem ser responsabilizados, buscando apenas em último caso, a resolução.

Fique claro que a rescisão negocial é uma hipótese cabível, mas subsidiária, que deve ser acionada apenas nos casos em que a violação for profunda, onde a boa-fé e confiabilidade foram tão contaminadas, que já não é mais possível seguir com a relação originária.

Entretanto, é preciso analisar com cuidado o caso concreto, para que não haja ingerência indevida e desarrazoada do Estado sobre as relações civis, o que, no caso do presente julgado, seria assim interpretado se o STJ obrigasse a IBM a contratar a Radiall contra a sua vontade e razões.

2 [...] A responsabilidade pela quebra da confiança possui a mesma ratio da responsabilidade pré-contratual, cuja aplicação já fora reconhecida pelo STJ (REsp 1051065/AM, REsp 1367955/SP). O ponto que as aproxima é o fato de uma das partes gerar na outra uma expectativa legítima de determinado comportamento, que, após, não se concretiza. O ponto que as diferencia é o fato de, na responsabilidade précontratual, a formalização de um contrato ser o escopo perseguido por uma das partes, enquanto que na responsabilidade pela confiança, o contrato, em sentido estrito, não será, ao menos necessariamente, o objetivo almejado. (...) 13. Recurso especial parcialmente provido, para reconhecer a responsabilidade solidária da IBM - Brasil pelo ressarcimento dos danos materiais (danos emergentes e lucros cessantes) à recorrente. (STJ - REsp: 1309972 SP 2012/0020945-1, Relator: Ministro LUIS FELIPE SALOMÃO, Data de Julgamento: 27/04/2017, T4 - QUARTA TURMA, Data de Publicação: DJe 08/06/2017, grifos nossos). 
Todavia, a decisão parece ser acertada, uma vez que eventuais prejuízos que alguém produzir em virtude de suas atitudes e relacionamentos, deve nessa proporção ser responsável pelas repercussões negativas quando esses atos atingem a esfera de terceiros, o que foi o que ocorreu.

Ora, uma vez se comportando como interessada, ainda que em tratativas pré-contratuais, dando claros interesses de eventual negócio viria a se concretizar, fornecendo inclusive subsídios técnicos, qualidade e quantidade, demonstrando nítida conduta de que tal transação iria prosperar, de maneira que há certa razoabilidade por parte da Radiall em desenvolver estrutura necessária para receber os pedidos e prestar o serviço e entregar os produtos com a qualidade que entender necessária.

Assim, dentro dessa linha, não é irrazoável concluir que os investimentos realizados pela Radiall para produzir as peças que iriam servir à IBM foram realizados em função e nos termos das relações que estavam sendo realizadas até então, por expectativas legítimas criadas pelas atitudes da eventual contratante, que conforme registro dos autos, chegou até mesmo fornecer informações técnicas e materiais acerca dos produtos que procurava.

Além do mais, pelo porte das empresas no litígio, se trata de circunstância que foge do padrão de normalidade, haja vista que não se trata de uma pessoa comum indo a uma loja de varejo dentro de um shopping center procurando por uma camisa. Mas sim de uma das maiores empresas de tecnologia do mundo, no caso da IBM, procurando por fornecedor para a viabilização de um projeto, onde em tratativas dava sinais concretos de fechamento de possível contrato.

Situação análoga, por exemplo, poderia ser aplicada dentro do contexto das startups para o caso de furto de bens intelectuais. Em função da assimetria existente entre os polos de uma eventual relação de investimento, o idealizador e proprietário de uma ideia ocupa essa qualidade muitas vezes de maneira informal. Não realiza qualquer registro ou patente que lhe dê a guarida jurídica necessária para realizar a sua tutela, o que ocorre muitas vezes por desconhecimento das normas, e assim, inocentemente, na tentativa de captar financiamento, expõe os conceitos de um projeto inovador e pioneiro para uma leva de investidores que maliciosamente escutam a tudo, mas posteriormente executam o projeto como se fossem autores originais do mesmo, sem a participação do idealizador.

Nessa senda, embora não venham a ser pactuadas relações jurídicas formais, o direito deve voltar os seus olhares também para o relacionamento pré-contratual, na linha da decisão relatada anteriormente do STJ. De modo que, caso demonstrado o comportamento de má-fé de investidores, que muitas vezes ocupam posição hierárquica superior, podendo considerar até mesmo uma hipossuficiência do investido sobre ele, a cronologia jurídica é irrelevante, sob pena de ressuscitar o caráter excessivo patrimonialista e formalista presente na codificação civil de 1916, e provocar graves injustiças sociais.

Destaque-se a previsão do artigo art. 157 do atual código civil quando fala no defeito do negócio jurídico, na modalidade da lesão. Esta está configurada quando uma pessoa, em função de sua premente necessidade ou inexperiência, assume obrigação manifestamente desproporcional ao valor da prestação oposta.

Segundo Adriano Godinho, “é evidente que não se demanda uma igualdade matemática das prestações, pois os contratos podem naturalmente conter em seu cerne um intuito lucrativo. O que não se admite é uma significativa desproporção das obrigações (...)" (Godinho, 2008, p. 103).

O pressuposto objetivo de sua configuração é a verificação de desproporção entre as prestações quando da celebração do contrato. Já o elemento subjetivo, pode se dar através da premente necessidade ou a inexperiência do contratante, esse último, o ponto que mais interessa a este trabalho. Isso porque, dentro do universo das startups, cujos fundadores usualmente são pessoas jovens ou inexperientes com o mercado, no começo da sua carreira profissional, é comum o relacionamento de pessoas inexperientes (founders) com agentes de mercado, com atuação de décadas e um longo caminho já percorrido, como nos casos de celebração de contratos de investimento-anjo.

A inexperiência a ser apurada no caso concreto deve levar em conta as especialidades e meandros que demandam o contrato que está sendo celebrado. No caso dos pactos de investimentos, as condições do mercado, o potencial crescimento da 
empresa, as habilidades pessoais necessárias para o desenvolvimento do negócio, valuation da startup no momento da celebração do pacto, o valor médio pago pelo mercado em circunstâncias análogas, bem como o preço médio cobrado por transações similares, entre outras condições adquiridas por vivências de momentos parecidos.

A inexperiência pode configurar-se, assim, tanto em relação ao sujeito completamente imaturo ou inculto, e, portanto, inabilitado à realização de quaisquer contratos, quanto em casos mais específicos, como se dá quando uma pessoa celebra uma modalidade negocial a cuja prática não esteja habituada. [...]

Deve-se adentrar nas especificidades características do contrato realizado e levar em consideração as condições psíquicas do agente, para que caiba identificar em sua vivência ou conhecimento acerca das circunstâncias fáticas em que se insere e, consequentemente, apurar se cabe ou não considerá-lo um inexperto (Godinho, 2008, p. 106).

Assim, tendo em mente sempre a estabilidade e segurança jurídica que as relações e contratos sociais devem guardar, é preciso que a desigualdade seja tamanha, que se justifique falar em violação à justiça contratual. Configurada a lesão, a anulação do contrato somente deverá ser decretada caso a parte beneficiada se recuse a reduzir o proveito obtido.

É o que dispõe o $\S 2^{\circ}$ do art. 157, cuja "disposição (...) é de enorme importância para a confirmação de uma contemporânea teoria geral dos contratos, pois, dentro dessa concepção lastreada nos princípios sociais contratuais, ela corresponde em última análise, à possiblidade de revisão contratual por parte do Poder Judiciário por meio do uso do instituto da lesão" (Cunha, 2007, p. 164).

Segundo Wladimir Cunha, a prioridade deve ser atendida pelo princípio da conservação dos contratos, verdadeira diretiva que ordena a conservação desses, em detrimento da anulação:

Toda sua conduta deverá ter em vista, imediatamente, o princípio da conservação dos contratos, e, imediatamente, a sua concepção social. O grande segredo está em vislumbrar o justo e o equilibrado, nos negócios lesivos, como categorias jurídicas abertas à concretização mediadora do juiz, o qual, somente assim, está agindo, dentro de uma concepção social, em conformidade com os princípios sociais dos contratos, em especial com o princípio da equivalência material das prestações contratuais, do qual a lesão é uma das mais importantes expressões. (Cunha, 2007, p. 165).

Há que se falar, ainda, sobre uma função punitiva para a responsabilidade civil para esses casos em que houver uma violação positiva do contrato, como sendo uma mensagem pedagógica sobre quais condutas são consideradas ilícitos civis, podendo acarretar não apenas a reparação do dano, mas verdadeira punição ao ofensor, superando uma visão limitada que enxerga nesse instituto civil uma função meramente reparatória. É que o processo de constitucionalização do direito provocou reformulações na responsabilidade civil, de maneira que a inspiração dos valores constitucionais fez com que princípios que eram desconsiderados até então passassem a fazer parte da aplicação desse instituto.

A dignidade da pessoa humana, a solidariedade social e a justiça distributiva são bons exemplos de tal renovação que provocou a releitura das funções da responsabilidade civil, redirecionando o foco da propriedade e do causador do dano, para a reparação do dano causado sobre a vítima.

A nova realidade social demanda pela atualização dos dispositivos do direito, inclusive a responsabilidade civil, para que se entregue uma solução jurídica satisfatória às novas situações conflituosas que venham surgir. Difícil tarefa para o intérprete do direito, o qual deve operar diante de uma variedade de exigências, interesses e necessidades, muitas vezes divergentes entre si.

Por este raciocínio, a proteção da pessoa humana provocou sobre a responsabilidade civil uma alteração de seu paradigma: anteriormente focado em punir o responsável que provocou o evento danoso, ela está agora mais voltada à reparação e à tutela da vítima, do lesado. Logo, a consequência foi o expressivo aumento das hipóteses de dano ressarcível e a perda de importância da função moralizadora, tida até então como um aspecto nuclear do instituto (Moraes, 2010, p. 322). 
A regulamentação legislativa do Código Civil de $2002^{3}$ sobre a responsabilidade civil se deu de maneira genérica, através de cláusulas gerais e conceitos vagos e indeterminados, carecendo de complementação do aplicador da norma. Assim, não é equivocado afirmar que esse instituto tem suas bases solidificadas pela jurisprudência, inclusive no que se refere às hipóteses de ressarcimento. Em certa parte, isso é positivo, vez que se torna mais fácil e rápida a adequação do ordenamento jurídico aos fatos e alterações sociais.

A redução da Responsabilidade Civil à função reparadora exclusivamente é negar efetividade à justiça, e se omitir diante de casos que violem direitos e interesses difusos e coletivos. Nessa linha de raciocínio, Nelson Rosenvald afirma que é hora de:

Revisitar o modelo jurídico das sanções punitivas privadas legado do direito romano clássico, certamente em outras bases, com as necessárias vicissitudes dos últimos 2.000 anos. A verdade é que amesquinhar o direito civil no escopo reintegratório, sem a capacidade de atuar sob o ponto de vista preventivo, implica em renúncia à efetividade, no binômio justiça/eficiência, sobremaneira no que diz respeito à violação a direitos da personalidade e atentados a interesses difusos e coletivos. (Rosenvald, 2014, p. 30).

No Brasil, boa parte da doutrina ${ }^{4}$ segue a corrente de duplo caráter da reparação do dano moral, com um caráter compensatório e outro punitivo.

Muito embora, em regra, o term sheet não se trate de contrato, ele pode adquirir essa característica em relação às obrigações que ficarem nele estipuladas, gerando expectativa de direito sobre o seu objeto, fazendo com que as negociações positivadas, para serem interrompidas devem ser justificadas pela ocorrência de um evento imprevisto que inviabilize o interesse financeiro do negócio (Rebelo, 2013).

É o que se chama de material adverse effect, onde o proponente encerra as negociações do contrato de investimento em virtude de uma motivação justificada, vez que um evento imprevisto reformulou completamente o cenário econômico que motivou os investidores a se interessarem pelo negócio.

Foi o caso da aquisição da Whitney do Brasil Holding, então proprietária da Universidade Veiga de Almeida (no Rio de Janeiro) e do Centro Universitário Jorge Amado (na Bahia), pela Anima Educação, no valor de R \$ 1.1 bilhão de reais, e que foi desfeita sob a alegação de que as mudanças ocorridas em 2014 nas regras do FIES, programa de financiamento estudantil do Governo Federal brasileiro, acabariam por alterar completamente o panorama que os motivaram a realizar a operação:

As relevantes mudanças no cenário econômico do País, especialmente no que diz respeito ao setor educacional que teve suas condições de atuação sensivelmente impactadas pelas recentes mudanças estruturais impostas pelo Governo Federal, afetaram, sobremaneira, as premissas e as perspectivas pelas quais foram negociadas as bases contratuais da operação com a Whitney Brazil Investments. (Koike, 2018, s/n).

Nessa esteira, pontua-se que, normalmente, chamam a atenção os artigos 427 e $428^{5}$ do Código Civil, que tratam sobre a vinculação do proponente em relação às propostas lançadas. Isso porque o term sheet é a exteriorização expressa e escrita da oblação, que pela inteligência desses artigos, vincularia o investidor a cumpri-la, desde que apresentasse uma justifica plausível para o contrário.

3 Art. 186. Aquele que, por ação ou omissão voluntária, negligência ou imprudência, violar direito e causar dano a outrem, ainda que exclusivamente moral, comete ato ilícito.

Art. 927. Aquele que, por ato ilícito (arts. 186 e 187), causar dano a outrem, fica obrigado a repará-lo.

4 "Quando se cuida do dano moral, o fulcro do conceito ressarcitório acha-se deslocado para a convergência de duas forças: caráter punitivo para que o causador do dano, pelo fato da condenação se veja castigado pela ofensa que praticou” (PEREIRA, 2001, p. 55. Segue o mesmo caminho Sergio Cavalieri Filho (2007, pp. 90-91).

5 Art. 427. A proposta de contrato obriga o proponente, se o contrário não resultar dos termos dela, da natureza do negócio, ou das circunstâncias do caso.

Art. 428. Deixa de ser obrigatória a proposta: [...]. 
Desse modo, esses acordos passaram também a prever uma cláusula esclarecendo que esse ato jurídico se trata de uma proposta não vinculante, evitando eventuais responsabilizações por parte dos proponentes quanto ao encerramento das negociações.

Uma vez assinada a carta de intenções, é natural do investidor cobrar alguns dados para que ele possa realizar uma auditoria sobre eles, para que possa se sentir confortável, confirmar os dados extraídos superficialmente, e então avançar para a fase do investimento. Esse procedimento é denominado de due diligence.

Os eventuais financiadores passam a ter acesso a todas as informações estratégicas e confidenciais da empresa, num procedimento de auditagem, a qual pode ser realizada sobre as seguintes vertentes:

a) Legal Diligence: analisa-se a estrutura societária, os litígios judiciais e administrativos em andamento, as propriedades, contratos, empréstimos e compliance, verificando o alinhamento dos atos empresariais com as respectivas normas de regulação em vigor. (Rose, 2014, s/n);

b) Business Diligence: examina-se o desempenho financeiro, como os bens, lucros, passivos e fluxos de fundo. A estrutura contábil, a exemplo dos documentos fiscais, tributos atuais, futuros e passivos. Bem como o plano de negócios, os resultados já apresentados, a visão para o futuro, entre outros. (Rose, 2014, s/n);

c) Market Diligence: busca investigar o posicionamento e inserção da empresa perante o mercado, a sua reputação, a demanda e a capacidade de entrega do produto/serviço da mesma. (Rose, 2014, s/n).

Esses dados são colhidos de certidões, contratos, relatórios e outros documentos que são entregues e analisados pelos investidores ou um terceiro contrato com essa finalidade específica, de onde se elabora um relatório final com base em tudo o que foi levantado, para que então o investidor faça a sua análise final quanto ao risco e seguro da operação, fazendo o seu próprio juízo de valor.

A relevância jurídica da due diligence encontra ressonância no Código Civil brasileiro, que no artigo 138 torna anulável os negócios jurídicos que forem celebrados com base em declarações de vontade emanadas por erros substanciais, que poderiam ter sido verificados por pessoas de diligência normal.

A realização dessas diligências afastaria a eventual alegação de defeito no negócio. Há, inclusive, caso interessante de litígio empresarial que foi julgado pelo STJ através do agravo em recurso especial 990.997 de origem do estado do Rio de Janeiro.

A lide em questão teve origem na venda de totalidade de quotas sociais de uma empresa que operava uma rede de postos de gasolina, que era subsidiária das parte rés desse processo, e vendedores do quinhão. O ponto de controvérsia foi a alegação dos autores de que houve omissão parcial por parte dos cessionários de informações importantes para a celebração do negócio jurídico, bem como a respectiva execução do contrato.

Acusaram-se, portanto, os autores de conduta incompatível com a boa-fé objetiva, uma vez que se informa que estes não haveriam feito a entrega de documentos que revelariam passivos e pendências em montante superior ao que fora exposto ainda nas negociações. Todavia, registre-se que houve comprometimento dos vendedores em indenizar todos os prejuízos que viessem a ser ocorridos, no montante de três milhões de reais, registrado em cláusula contratual.

Assim, o pedido de anulação do negócio por vício de dolo foi julgado improcedente pelo juízo de primeiro grau, sob a fundamentação de que se estava diante de um negócio de transferência societária de complexidade, repleto naturalmente de uma série de riscos, que está distribuído entre as partes quando da elaboração do pacto, de modo que não há que se falar em vulnerabilidade de nenhuma das partes em relação à outra; desconsiderar isto significaria violar a liberdade contratual e o equilíbrio econômico das partes.

Além do mais, segundo relatório da corte superior, há demonstração cabal nos autos de que o processo de transferência societária foi precedido por longa negociação e realização de due diligence, através do fornecimento de informações necessárias para o conhecimento da empresa, dos riscos e potenciais. 
Com base em tais informações, o julgamento pelo não provimento do recurso dos ora compradores, pelo STJ, parece correto, posto que a mera alegação de omissão geral, sem indicação específica de elementos que comprovem o que se pretende, posto que a tutela judicial de negócios jurídicos privados só deve ser legitimado diante de violações de regras legais ou princípios fundamentais de aplicabilidade horizontal, o que não foi o caso em questão.

Isso porque a natureza do negócio jurídico celebrado pressupõe complexidade e equivalência econômica, de modo que diante da realização de procedimento de due diligence, é razoável presumir que para este caso, qualquer homem médio poderia tirar conclusões e elaborar propostas que o vinculariam nos termos do contrato, haja vista que atuaram os agentes com plena autonomia de suas vontades e sem disparidade considerável entre si.

Nesse sentido, pode-se falar que houve uma distribuição proporcional e razoável dos riscos relativos aos passivos e pendências da pessoa jurídica negociada, tendo em vista que além da previsão negocial ter estipulado ainda um montante de três milhões para eventuais indenizações decorrentes da concretização desses eventos (im)previsíveis, a anulação desse negócio jurídico poderia configurar em interferência indevida e injusta do Estado-Juiz.

Ato contínuo, visando à autopreservação da startup, é decorrência natural dessa abertura de dados os fundadores solicitarem a assinatura de um Non-Disclousure Agreement - NDA, que é um acordo de confidencialidade que visa defender as informações privilegiadas e estratégicas.

\section{Considerações Finais}

Ante o exposto, percebe-se que as startups necessitam, para seu desenvolvimento pleno, de alguns instrumentos jurídicos para dar alicerce e incentivar as atividades desempenhadas na esfera das startups, principalmente no tocante a segurança jurídica e crescimento econômico.

Ademais, verifica-se que a contratação das startups segue um rito básico, mas com nuances peculiares, sendo assinatura de uma carta de intenções, seguido pela assinatura de um acordo de confidencialidade, posteriormente o processo de auditoria e, por fim, a assinatura do termo de investimento.

Nesta esteira, levando em consideração essa necessidade de assegurar, de forma eficaz, o crescimento econômico inerente ao mercado, acreditamos que investigações como esta devem ser prosseguidas. Sendo assim, como sugestão para continuidade de discussões nesse sentido, analisar, à luz do Código Civil, de que modo os contratos empresarias podem ser implementados com o fito de melhor exercer sua função impulsionadora de segurança jurídica e crescimento econômico, contribuirá para o fortalecimento e planejamento de estratégias de atenção aos empresários, assim como desenhar e formular novos e mais efetivos caminhos em direção à efetivação dos direitos inerentes aos empresários.

\section{Referências}

Cunha, W. A. M. F. (2007) Revisão Judicial dos Contratos: Do Código de Defesa do Consumidor ao Código Civil de 2002. (1ª . ed.): Método.

Ehrhardt, M. Jr. (2014). Responsabilidade civil pelo inadimplemento da boa-fé: Fórum.

Feigelson, B., Fontenele, E., \& Fonseca, V. C. (2018). Direito das Startups: Saraiva Educação.

Godinho, A. M. (2008). A Lesão no Novo Código Civil Brasileiro. (1ª. ed.): Mandamentos, 2008.

Lei $n^{\circ}$ 10.406, de 10 de janeiro de 2002. Institui o Código Civil. http://www.planalto.gov.br/ccivil_03/leis/2002/110406compilada.htm

Koike, Beth. Com mudanças no Fies, Anima cancela aquisição da Whitney Brasil. https://www.valor.com.br/empresas/4017506/com-mudancas-no-fies-animacancela-aquisicao-da-whitney- brasil

Moraes, M. C. B. (2010). Na medida da pessoa humana: estudos de direito civil: Renovar.

Pereira, C. M. S. (2001). Responsabilidade civil. (9a. ed.): Forense, 2001. 
Research, Society and Development, v. 10, n. 6, e35710613737, 2021

(CC BY 4.0) | ISSN 2525-3409 | DOI: http://dx.doi.org/10.33448/rsd-v10i6.13737

Rebelo, N. S. A. (2013). A Sociedade Empresária e a Captação de Recursos de Private Equity e Venture Capital: Estudo Interdisciplinar do Financiamento Empresarial: Buqui.

Rose, D. S. (2014). Angel Investing: The Gust Guide to Making Money and Having Fun Investing in Startups. Hoboken: Wiley.

Rosenvald, N. (2014). As funções da responsabilidade civil: a reparação e a pena civil: Atlas.

Tepedino, G. (2002). Crise de fontes normativas e técnica legislativa na parte geral do Código Civil de 2002. A Parte Geral do Novo Código Civil (Estudos na Perspectiva Civil-Constitucional): Renovar. 